\title{
The Assessment of the Unheard Stories of Orphan Children Infected and Affected by the HIVIAIDS Epidemic: A Case Study in Alice Eastern Cape, South Africa
}

\author{
T. Pitso \\ Department of Psychology, University of Fort Hare, P. Bag X1314, Alice 5700, RSA \\ Email: tsoloz2002@yahoo.co.uk
}

\author{
Doi:10.5901/mjss.2014.v5n10p560
}

\begin{abstract}
The epidemic in sub-Saharan Africa has already orphaned a generation of children and it was projected that by 2010, 18 million African children under the age of 18 will be orphans from AIDS (UNICEF, 2006). It has been estimated that more than 2 million children have already been orphaned in South Africa and those infected and affected are mostly from the poor socio-economic background (Fourie and Meyer, 2010). A qualitative study has investigated 12 orphans who were selected by means of snowball sampling method. The informed consent was acquired from the guardians and parents of these children and all the participants were appraised on issues to do with confidentiality. Both face to face interview and open-ended questionnaires were used to collect data. The findings were that these children experience grief and depression, they are physically abused by their guardians, sexual abuse and this leads trauma, they have fear of disclosing their real experiences for the fear of being assaulted, cannot concentrate at school hence their academic performance is poor and some gave to achieving their future aspirations. The study recommended that beyond food and shelter, these orphans need a psychological support after the loss parents so that they can acquire the skills of resilience to daily combats.
\end{abstract}

Keywords: Orphans, HIV/AIDS, Infection, Affection and Epidemic.

\section{The Life Experience of the Orphans of the Epidemic HIVIAIDS}

Brough (2007) found out that the HIVIAIDS orphans have a particularly difficult experience as they often suffer physical and emotional neglect long before the passing of their parents. In most cases, these children witness their parents succumb to AIDS, as a result, they suffer from psychological and emotional harm. The state of being an orphan often results in a move from their home of upbringing where they studied, were having siblings, and friends and recite in a new and traumatic situation which is not palatable for them to recover their loss.

According to Ndjolo ,Njock, Ngowe, Ebogo, Toukam, Nko, and Bengono, (2004), children whose parents are infected or have died of HIVIAIDS often face discrimination even if they are not infected themselves. This discrimination often results in these children being denied the required attention and care that they desperately need. As a result, even their closest families often show lack of support and they end up being exposed to psychosocial challenges such as early parenthood.

In some cases, parents become so weak to work and these children are forced to drop-out of school and become unqualified bread-winners. This situation in a way exposes them to challenges such as social exchange of favours, the state whereby those who have can easily exploit the have-nots. Brough (2007) found that children who grow up with irresponsible parents or without parents are highly vulnerable to contracting parasitic diseases such as HIVIAIDS. Furthermore, these children are at a higher risk of exploitation, unemployment and other social inequalities.

According to UNICEF report (2006), 18 million children were estimated to have been orphans by the year 2010. As a result, these children face trauma after the death of the parents and distress becomes the immediate experience. Juma (2001) posited that support for such children decline with time and they end up facing the daily challenges on their own and this in way leave them in a susceptible situation of being victimized by the psychosocial challenges such as dating old people who can provide the means of livelihood. Equally so, orphans may be disadvantaged by the pre-existing low socio-economic status at the time of their parents' death as well as their biological distance from bread winners and decision makers in the households in which they are placed (Ainsworth and Filmer, 2002).

\section{The Problem}

Children orphaned by HIVIAIDS may have a myriad of unique problems such as emotional neglect, emotional trauma, 
exploitation, identity confusion and psychological distress. Their problems may emanate from the community's perception of HIVIAIDS and pre and post death social conditions that they experience. Furthermore, a little is known about their welfare and the results of being orphans.

\section{The Findings}

\subsection{Their relationship with their guardians}

Out of twelve respondents, ten indicated their dissatisfaction of staying with their guardians.

Resondent No 1: I am going to tell you as she will beat me. Please don't tell her. I am staying well with Makazi (Aunt). I do all the work household chores and her children are lazy and doing nothing.

Respondent No 5: It is better to stay in the street that with my guardians. At times I feel like killing myself. I wish that my parents were here.

\subsection{Are they abused by their guardians?}

Some of the respondents showed low level of understanding between abuse and rebuke. As some of the will indicate that their guardians are beating them but not abusing them.

Respondent No 2: My uncle beats me when I arrive late from after school classes. He told me to come home immediately after school and do the gardening.

Respondent No 4: My guardians are not working so I have to sell the fruits so that we can eat at home. And at times I get part time job from the local shops to load and unload their stock.

\subsection{Do you have any time to play with your peers?}

Most of the respondents indicated that they have a very little time to play as they are expected to do household chores, gardening and some even go to work.

Respondent No 7: I don't have to play because there is a lot of work at home. My peers like us to play .But I only play with them when I'm at school.

Respondent No 10: I only manage to play when my guardians went to drink or when they are drunk and asleep. I don't have to play much because I have a lot of work to do.

Respondents 12: Some children are not allowed to play with me. I think they don't like me. Even their parents do not allow them to visit me. They just play inside their yard. I don't have friends.

\subsection{How do educators treat you?}

Some of the respondents indicated that some of the educators laugh at them and make jokes about them in class. As a result, some have dropped-out of school.

Respondent No 1: I don't want to go to school anymore because my classmates and the educators always laugh at me and some even say that $i$ wear dirty clothes.

Respondent No 5: Some educators beat me more that my classmates, especially when I have missed the classes. I am always tired at school and I feel like sleeping.

Respondent No 7: Some students come to school with nice food and at times I feel like stealing them because they hardly give me some. I always feel hungry at school because there is no enough food at home.

\section{Conclusion}

Most of the HIVIAIDS orphans do go to school but get less support from their educators and their fellow students, as they face a stigma and discrimination in the school environment. As result, some do drop-out and find a refugee in streets which leaves them vulnerable to psychosocial challenges such as rape, child-labour and exploitation.

The home environment leaves them with an element of mistrust due to the ill-treatment that they experience from their guardians. Consequently, they experience emotional problems and psychological distress.

The reported cases of rape and sexual abuse leave their perpetrators in jail but the victims (orphans) with 
unattended trauma.

A large number of the HIVIAIDS affected children is known but a little is known about their welfare and the consequences of being an orphan.

These orphans do not have psychological and effective support from their guardians and the community. Hence they suffer emotional, physical and social neglect.

\section{Recommendations}

The study aims at improving the welfare of HIVIAIDS orphans for posterity since these children are part of the future.

Since orphan-hood is quite common in almost every community, reinforcement of the coping mechanisms is highly recommended.

No vaccines are available to the affected, the preventive methods should be advanced and upgraded for the betterment of controlling the spread of HIVAIDS and the better care of the affected should remain a priority in coping with the scourge.

HIVIAIDS awareness programmes offered by both the government and the non-governmental organizations will be challenged to tally with the nature of the HIVIAIDS infections, affections and its prevalence.

Furthermore, both traditional and community development and care programmes should be strengthened in order to equip these orphans with the resilience skills to combat the daily challenges.

The concept of "Ubuntu" meaning the state of being humane should be reinforced in order to positively shape the minds of the individuals and the community at large to the state of emotional intelligence.

\section{References}

Brough, C. (2007). AIDS Orphans in Sub-Saharan Africa. The AIDS Pandemic. BlogSpot. Accessed on 11/10/09. http:/the-aidspandemic.blogspot.com

UNICEF. (2006). Epidemiology of Health and Vulnerability among Children Orphaned and Made Vulnerable by HIVIAIDS in sub-Saharan Africa: $19^{\text {th }}$ August, 2006.

Fourie, P. and Meyer, M. (2010). The Politics of AIDS Denialism: South Africa' Failure to Respond. Ashgate Publishing Limited. U.S.A.

Ndjolo, A., Njock, R,. Ngowe N.M., Ebogo, M.M.B., Toukam, M., Nko, S and Bengono, G. (2004) Early ENT Manifestations of HIV Infections /AIDS. An Analysis of 76 Cases Observed In Africa: 02/2004:125 (1):39-43.

Juma, M. (2001). Coping with HIVIAIDS in Education: Case Studies of Kenya and Tanzania. Commonwealth Case Studies in Education.

Ainsworth, M and Filmer, D. (2002). A Generation at Risk: The Global impact of HIVIAIDS on Orphans and Vulnerable Children: Cambridge University Press. New York. 